\title{
REMOVAL OF CALCIUM HYDROXIDE MEDICAMENT FROM ROOT CANAL WALLS - A REVIEW OF THE DIFFERENT TECHNIQUES
}

\author{
Tsvetelina Borisova-Papancheva, Slavena Svetlozarova
}

\author{
Department of Conservative Dentistry and Oral Pathology, Faculty of Dental Medicine, \\ Medical University of Varna
}

\begin{abstract}
INTRODUCTION: Calcium hydroxide is used widely as an intracanal medication dressing due to its antibacterial activity. It is left into the root canal for a different period of time. Intracanal calcium hydroxide is usually removed by the use of instrumentation and irrigation. The residual material may interact with the root canal sealer and interfere with its sealing ability.

AIM: The aim of this article is to review the literature in order to compare the main techniques that can be used to remove calcium hydroxide from the root canal system.

RESULTS: Intracanal calcium hydroxide is usually removed by the use of continuous irrigation, in conjunction with rotary or hand instruments, sonic or ultrasonic activation of the irrigants.

CONCLUSION: None of the described techniques is able to provide a complete removal of the intracanal calcium hydroxide from the root canal walls in all clinical cases, because of the complexity of the root canal system of every tooth. There is no standard protocol and different techniques should be applied and combined in order to achieve clean root canal walls before the definitive obturation of the root canal system.
\end{abstract}

Keywords: calcium hydroxide removal, intracanal medicament, conservative treatment, sealing ability

\section{INTRODUCTION}

It has been established that bacteria and their products play a key role in the initiation and progression of pulpo-periapical pathology $(1,2)$. Elimination of the bacteria from the root canal system is normally accomplished by mechanical instrumentation along with the application of various irrigating solutions and antibacterial agents (1). The use of intracanal medication after chemomechanical preparation

\footnotetext{
Address for correspondence:

Tsvetelina Borisova-Papancheva

Faculty of Dental Medicine

Medical University of Varna

84 Tzar Osvoboditel Blvd

9000 Varna

e-mail:dr_borisova@abv.bg
}

Received: November 7, 2018

Accepted: December 12, 2018 provides a better chance of periapical repair, since the mechanical preparation by itself does not reach all the lateral root canals or dental tubules (3). Calcium hydroxide is highly recommended as an interappointmentintracanal endodontic dressing because of its antibacterial activity against most of the bacterial species, identified in endodontic infections (1).

Calcium hydroxide has been used in dentistry for over a century. It has been described in a number of applications such as in cases with root resorption, as an intracanal medication and root canal sealer. The material provides a lot of advantages, but also has some limitations $(4,5)$. In 1920 calcium hydroxide was introduced in dentistry by Herman as a pulpcapping material but today it is widely used in the field of endodontics $(4,6,7)$.

Chemically, calcium hydroxide is a strong base with $\mathrm{pH}$ about 12.5-12.8, which dissociates into calci- 
um and hydroxyl ions (8).As an intracanal dressing, the material is available in different forms.

The wide use of calcium hydroxide in the field of endodontics is due to its numerous advantages, such as (9):

$\diamond$ Initial bactericidal effect, then a bacteriostatic one;

$\diamond$ Promotion of healing and repair;

$\diamond$ High pH that stimulates the fibroblasts;

$\diamond$ Can help stop internal resorption

$\diamond$ It is inexpensive and easy to use.

On the other hand, calcium hydroxide has also some disadvantages, such as (9):

$\diamond$ Does not adhere to dentin or resin restorations.

$\diamond$ Degrades upon tooth flexure.

$\diamond$ Dissolves over time.

The application of calcium hydroxide at intervals of at least seven days is able to eliminate or at least reduce the total number of bacteria surviving after the biomechanical preparation (10). It has a wide range of antimicrobial activity, but limited effect against E. faecalis and C. albicans. It is also an effective anti-endotoxin agent (6). The effect of calcium hydroxide on pro-inflammatory cytokines was studied and it was concluded that it leads to denaturation of pro-inflammatory mediators such as interleukin1a (IL-1 $\alpha$ ), tumornecrosisfactora (TNFa) and calcitoningene-relatedpeptide (CGRP), which is a potential mechanism by which calcium hydroxide contributes to periapical repair (11).

Different techniques can be used for the placement of calcium hydroxide in the canals, namely: syringes, finger spreaders, rotary lentulo spirals, specially designed paste carriers, etc. (12).

Incomplete removal of the material from the root canal may affect sealer performance and the long-term prognosis of the endodontic treatment $(13,14)$.

\section{MATERIALS AND METHODS}

We have gathered articles and compared results from numerous studies in order to summarize some of the main techniques for removal of calcium hydroxide from the root canal system, as well as compare the different methods to each other according to their efficiency.

\section{RESULTS}

Cleaning of the root canal system may be achieved by delivering effective irrigation, solution activation as well as by direct contact with all canal walls, especially in the apical third.Several methods have been described to remove calcium hydroxide from the root canal system. The most commonly applied method is using a master file to the working length in conjunction with ethylenediaminetetraacetic acid (EDTA)and $\mathrm{NaOCl}$ irrigation (15). Using rotary files, sonic and ultrasonic activated tips with irrigation have also been recommended. It has been reported that continuous irrigation with vibrating motion may have positive effect on the cleaning process, particularly in the apical third of the canal, which is the most difficult part to clean (16).

Lambrianidis et al. (1) in 1999 investigated whether differences in the composition of calcium hydroxide preparation influences the removal efficiency of irrigation solutions. A total of 51 extracted single-rooted teeth were divided into 3 groups, where different type of calcium hydroxide and different irrigant, namely saline, EDTA in combination with $\mathrm{NaOCl}$, and $\mathrm{NaOCl}$ were used. The results of the study revealed that none of the methods used was efficient in removing the entire dressing from the root canal walls, leaving $25-45 \%$ of the surface of the walls covered with calcium hydroxide. In all the observedteeth the irrigants were delivered into the root canal system with a syringe, which was proved by the study tonot be efficient enough, although for the root canal instrumentation a Gated Glidden burr was used, allowing the irrigation needles to reach most areas of the root canal system. The present study also revealed that the calcium hydroxide content in the intracanal dressing does not influence the removal efficacy.

Rödig et al. (17) compared the efficacy of different irrigant solutions $(1 \% \mathrm{NaOCl}, 10 \%$ citric acid and $20 \%$ EDTA) in the removal of calcium hydroxide from the root canal walls. The volume of irrigant was $20 \mathrm{mLand}$ the irrigation time was $5 \mathrm{~min}$. The authors concluded that the best results were found for irrigation with EDTA and citric acid. The combination of irrigants in the study did not result in improvement in terms of cleanliness. 
Taşdemir et al. (18) also compared in a study the efficacy of several techniques for the removal of calcium hydroxide from root canals. The authors concluded that significantly less residual material was obtained with a CanalBrush and passive ultrasonic activation of $\mathrm{NaOCl}$ than with syringe delivery of $\mathrm{NaOCl}$ and $\mathrm{NaOCl}$ together withEDTA. None of the used in the study techniques was able to remove the calcium hydroxide intracanal dressing completely.

Passive ultrasonic irrigation with $2 \% \mathrm{NaO}-$ $\mathrm{Cl}$ was also proven to be more efficient in removing calcium hydroxide paste from artificial root canal grooves than the syringe delivery of $2 \% \mathrm{NaOCl}$ or water (19).

Another study (20) compared the efficiency of removing calcium hydroxide/chlorhexidine gel, calcium hydroxide/chlorhexidine solution and calcium hydroxide/saline pastes with the use of irrigation with $\mathrm{NaOCl}$ and EDTA solution. The role of the patency file in the cleanliness of the apical third of the root canal was also evaluated and proven beneficial in the removal of the medicament in the apical third of straight root canals.

Different studies (21) compared ultrasonically activated irrigation and syringe irrigation according to the ability of removal of calcium hydroxide from the root canal. Ultrasonically activated irrigation in general was found to be significantly more efficacious in all of the studies.Ultrasonically activated irrigation and sonic irrigation were also compared. In the reviewed studies (21) the EndoActivator system (Advanced Endodontics, Santa Barbara, CA) was used to perform the sonic activation. The sonic tip was activated at $2 \mathrm{~mm}$ from the working length in all of the reviewed studies. Some of the studies reported the superiority of ultrasonic activation, whereas the other half reported no significant differences between both techniques.

A comparison between the ultrasonically activated irrigation and negative pressure systems (EndoVac device) was also performed and proved the ultrasonically activated one superior to the ANP irrigation (21).

Ultrasonically activated irrigation was also compared to other methods, used for the removal of calcium hydroxide. One study reported the superior- ity of ultrasonic irrigation over the use of rotary files (ProTaper, Dentsply, Switzerland) (22).

Bottcher et al. (23) reported that there is no significant difference between ultrasonically activated irrigation and the use of a hand file. Ma et al. (24) proved that the Gentle Wave System (Sonendo, CA), which has been developed for cleaning the root canal system and uses advanced fluid dynamics to deliver irrigating solutions, is better in the removal of calcium hydroxide than the ultrasonically activated irrigation.

Pabel et al. (25) published the results of a study, comparing the ability of different techniques and namely passive ultrasonic irrigation, hydrodynamic irrigation using RinsEndo, sonic irrigation using EndoActivator, motor-driven plastic brush and a manual irrigation with a syringe, to remove calcium hydroxide from the root canal walls. Complete removal of the calcium hydroxide could not be achieved with any of the investigated techniques. The passive ultrasonic irrigation assured the highest degree of cleanliness and the coronal grooves in the root canal walls showed more remaining calcium hydroxide than the apical ones. Ultrasonically activated irrigation enhanced calcium hydroxide removal from complex root canal anatomy (26). The removal efficacy of calcium hydroxide seemed to be dependent on the use of EDTA solution in the irrigation protocol, possibly by chelation of calcium ions. Based on a study, conducted in 2017 (26), radiographic analysis may be considered as a reliable method for the assessment of calcium hydroxide removal.

Wang et al. (27) studied in vitro the efficacy of removing calcium hydroxide from curved root canals and proposed a calcium hydroxide removal protocol. The authors described it as a stable and effective method to remove calcium hydroxide from the root canal system. They recommended using EDTA $17 \%$ or $10 \%$ citric acid with Endo Activator or passive ultrasonic irrigation. The protocol uses more than 10 mLof irrigant (Fig. 1).

Another study (28) concentrated on the efficiency of laser-activated irrigation (erbium, chromium:yttrium-scandium-gallium-garnet (Er,Cr:YSGG) and concluded that it facilitated the removal of the medicament from standardized grooves, while the type of irrigating solution - EDTA or phyt- 


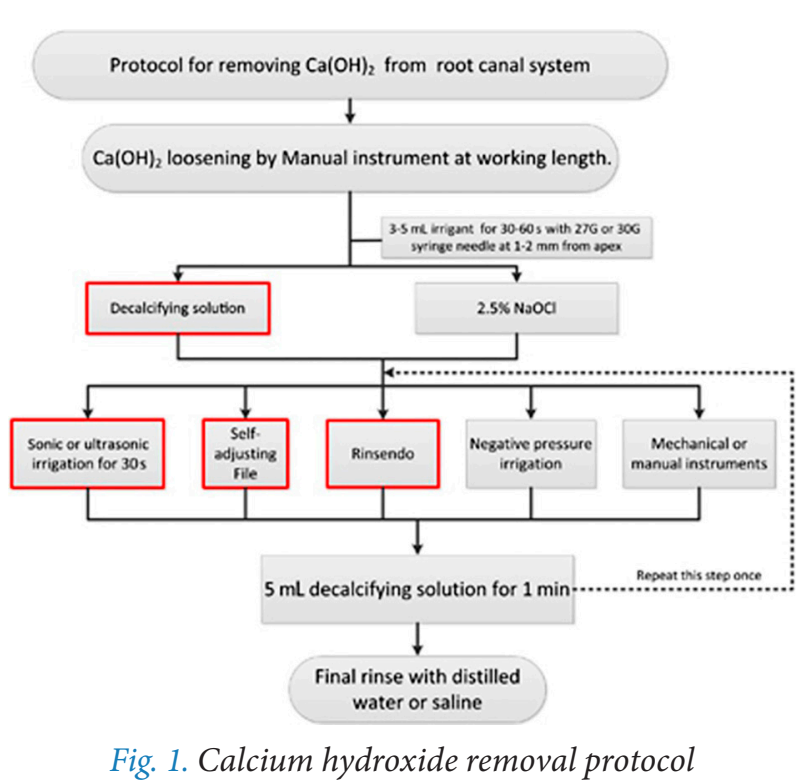

ic acid, used as final rinse, did not play a significant role in the removal process.

Laser activated groups of teeth obtained significantly less residual calcium hydroxide than the needle-irrigated ones. No significant difference was observed among the irrigants: EDTA, QMix 2 in 1 and paracetic acid (29). On the contrary, the Er:YAG laser did not improve the calcium hydroxide removal during conventional root canal therapy irrigation with EDTA and $\mathrm{NaOCl}$ under the conditions of a study, performed by Kaptan et al. (30).

The removal of radioactively marked calcium hydroxide from the root canal system was investigated (31). The authors proved that increasing the irrigation volume led to a significant decrease of residual calcium hydroxide, however no irrigation procedure was able to remove calcium hydroxide completely. Irrigation of $8 \mathrm{mLvolume}$ of alternating $40 \%$ citric acid and $3 \% \mathrm{NaOCl}$ was proven by the study to be the most effective.

Faria et al. (32) concluded that the rotary instrumentation, combined with EndoActivator, EndoVac and passive ultrasonic activation is more efficient in removing calcium hydroxide from the root canal walls than the rotary instruments combined with conventional needle irrigation.

The use of SAF-system (Self-Adjusting File, ReDent-Nova, Israel)in combination with EDTA and $\mathrm{NaOCl}$ enhanced calcium hydroxide removal in comparison with the use of only $\mathrm{NaOCl}$ with SAF.
Passive ultrasonic irrigation and SAF were proved more efficient than EndoVac and conventional syringe irrigation in the removal of calcium hydroxide from artificial grooves in the apical third of the root canal, according to another study (33).

In the early 1977 Margelos et al. (34) demonstrated that $15 \%$ EDTA or $\mathrm{NaOCl}$ alone does not remove the calcium hydroxide from the root canal walls, but their combination, along with hand instrumentation, improves the calcium hydroxide removal.

Since that discovery a lot of new techniques and methods have been developed, making the proper irrigation of the root canal system more achievable. However, none of the irrigants was proved to be able to remove the residual calcium hydroxide completely in vivo. Maleic acid (7\%), a chelating agent, has been found to possess better smear layer removal quality when compared to $17 \%$ EDTA (35).

Ballal et al. (36) conducted a study the purpose of which was to compare the efficacy of $10 \%$ citric acid, 17\% EDTA and 7\% maleic acid using ultrasonic activation in the removal of calcium hydroxide as an intracanal medicament. The study concluded that none of the irrigants could remove calcium hydroxide - iodoform - silicone oil mixture completely. A total of $7 \%$ maleic acid and $10 \%$ citric acid removed the calcium hydroxide mixture significantly better than the $17 \%$ EDTA solution.

\section{DISCUSSION}

The different results reported by the different studies can be explained with the complexities of the different methodologies used. Different types of calcium hydroxide, irrigation times, solutions, and outcome measurements are used. Numerous studies prove that neither irrigation, nor different removal methods could provide complete removal of the intracanal dressing from the root canal walls $(1,18,19,29,31,37)$. Remnants of calcium hydroxide in simulated root resorption cavities were found in all experimental groups of teeth, regardless of the final irrigation technique used (38).

On the other hand, calcium hydroxide should be removed completely from the root canal system, because the persistence of calcium hydroxide may interfere with the sealing ability of endodontic sealers and affect the adhesion of endodontic sealers to the canal walls $(13,39)$. 
Tsvetelina Borisova-Papancheva, Slavena Svetlozarova

Eymirli et al. (24) conducted a study aimed to evaluate the influence of calcium hydroxide on the bond strength to root dentin of the epoxy resinbased AH Plus jet (Dentsply) and calcium hydroxide-based Apexit Plus (IvoclarVivadent) after using different calcium hydroxide removal techniques. The bond strength was measured by the push-out bond method. The study indicated that the bond strength was influenced only in the case with AH Plus, while for Apexit Plus there were no statistically significant differences. As an explanation for the results it was suggested that calcium hydroxide burdened the penetration of AH Plus into the dentinal tubules.

An ideal root canal filling material should adhere to the root canal dentin and resist dislocation forces. Therefore, the sealer should bond as much as possible with the root canal dentin (41).

In their study, Gokturk et al. (42) proved that the prior application of calcium hydroxide did not significantly affect the adhesion of AH Plus, MTA Fillapex and Total Fin BC sealer, when a matchingtaper-single-cone obturation technique was used. Similar results are reported from another study (43), which concluded that calcium hydroxide did not affect the bond strength of the epoxy resin-based sealer in the middle and apical thirds. A study, conducted in 2012 (44), even proved that calcium hydroxide, used as intracanal medication for 14 days, had a positive influence on the bond strength of epoxy resins sealers $(\mathrm{AH})$ to the dentin.

On the other hand several studies $(17,45)$ have observed that calcium hydroxide reduces dentinal permeability by physically blocking the tubules.

The different results from the reviewed articles and studies may be due to the different methologies of the experiments. Deformation of the gutta-percha during the push-out bond test may also lead to incorrect measurements (46). The use of core material in root canal fillings presents with some disadvantages even without the use of intracanal dressing of calcium hydroxide, such as voids formation between the core material and sealer and lack of homogeneity (41).

\section{CONCLUSION}

Calcium hydroxide as an intracanal medicament has been widely used and its main advantages and antibacterial properties are well known. Re- moving all of the intracanal material until achieving clean root canal walls before obturation of the root canal is still sometimes problematic. The removal of calcium hydroxide has been investigated using various irrigants and techniques.

Despite the developing of superior devices and technologies, allowing the irrigants to reach a wider part of the root canal system, the complete removal of the calcium hydroxide before obturation is still not always guaranteed. Clinicians should put extra efforts and combine different irrigants and techniques in order to minimize the residual calcium hydroxide in the root canal walls and to create favorable conditions for optimal sealing ability of the root canal obturation material.

\section{REFERENCES}

1. Lambrianidis T, Margelos J, Beltes P. Removal efficiency of calcium hydroxide dressing from the root canal. J Endod. 1999; 25(2): 85-8. doi: 10.1016/ S0099-2399(99)80002-8.

2. Croitoru IC, CrăiŢoiu Ş, Petcu CM, Mihăilescu OA, Pascu RM, Bobic AG, et al. Clinical, imagistic and histopathological study of chronic apical periodontitis. Rom J Morphol Embryol. 2016; 57(2):719-28.

3. Santos Soares SM, Brito-Júnior M, de Souza FK, Zastrow EV, Cunha CO, Silveira FF, et al. Management of cyst-like periapical lesions by orthograde decompression and long-term calcium hydroxide/ chlorhexidine intracanal dressing. J Endod. 2016;42(7):1135-41. doi: 10.1016/j.joen.2016.04.021.

4. Ba-Hattab R, Al-Jamie M, Aldreib H, Alessa L, Alonazi M. Calcium hydroxide in endodontics: An overview. Open J Stomatol. 2016;6: 274-89. doi: 10.4236/ojst.2016.612033

5. Desai S, Chandler N. Calcium hydroxide-based root canal sealers: A review. J Endod. 2009; 35(4):475-80. doi: 10.1016/j.joen.2008.11.026.

6. Mustafa M, Saujanya KP, Jain D, Sajjanshetty S, Arun A, Uppin L, et al. Role of Calcium Hydroxide in Endodontics: A Review. Glob J Med Public Health. 2012; 1(1): 66-70.

7. Fuks AB .Vital pulp therapy with new materials for primary teeth: New directions and treatment perspectives. J Endod. 2008; 34(7 Suppl):18-24. doi: 10.1016/j.joen.2008.02.031.

8. Mohammadi Z, Dummer PMH. Properties and applications of calcium hydroxide in endodontics and 
dental traumatology. Int Endod J. 2011;44(8):697730. doi: 10.1111/j.1365-2591.2011.01886.x.

9. Agrawal V. Calcium hydroxide: A miracle munition. Indian J Dent Res Rev. 2011; 1:16-8.

10. Mohammadi Z, Shalavi S, Yazdizadeh M. Antimicrobial Activity of Calcium Hydroxide in Endodontics: A Review. Chonnam Med J. 2012;48(3):133-40. doi: 10.4068/cmj.2012.48.3.133.

11. Khan AA, Sun X, Hargreaves KM. The effect of calcium hydroxide on pro-inflammatory cytokines and neuropeptides. J End. 2008; 34(11):1360-1363. doi: 10.1016/j.joen.2008.08.020.

12. Tan JME, Parolia A, Pau AKP. Intracanal placement of calcium hydroxide: A comparison of specially designed paste carrier technique with other techniques. BMC Oral Health. 2013;13: 52. doi: 10.1186/1472-6831-13-52.

13. Barbizam J, Trop M, Teixeira EC, Tanomaru-Filho M, Teixeira F. Effect of calcium hydroxide intracanal dressing on the bond strength of a resin-based endodontic sealer. Braz Dent J. 2008;19(3):224-7.

14. Faria G, Kuga M, Ruy A, Aranda-Garcia AJ, Bonetti-Filho I, Guerreiro-Tanomaru JM, et al. The efficacy of the self-adjusting file and protaper for removal of calcium hydroxide from root canals. J Appl Oral Sci. 2013;21(4):346-50. doi: 10.1590/1678-775720130034.

15. Balvedi R, Versiani M, Manna F, Biffi J. A comparison of two techniques for the removal of calcium hydroxide from root canals. Int Endod J. 2010;43(9):763-8. doi: 10.1111/j.1365-2591.2010.01718.x.

16. Gu LS, Kim JR, Ling J, Choi KK, Pashley DH, Tay FR. Review of contemporary irrigant agitation techniques and devices. J Endod. 2009;35(6):791804. doi: 10.1016/j.joen.2009.03.010.

17. Rödig T, Vogel S, Zapf A, Hülsmann M. Efficacy of different irrigants in the removal of calcium hydroxide from root canals. Int Endod J. 2010;43(6):519-27. doi: 10.1111/j.1365-2591.2010.01709.x.

18. Taşdemir T, Çelik D, Er K, Yildirim T, Ceyhanli KT, Yeşilyurt C. Efficacy of several techniques for the removal of calcium hydroxide medicament from root canals. Int Endod J. 2011;44(6):505-9. doi: 10.1111/j.1365-2591.2011.01854.x.

19. Van der Sluis LWM, Wu MK, Wesselink PR. The evaluation of removal of calcium hydroxide paste from an artificial standardized groove in the api- cal root canal using different irrigation methodologies. Int Endod J. 2007; 40(1):52-7. doi: 10.1111/j.1365-2591.2006.01182.x.

20. Lambrianidis T, Kosti E, Boutsioukis C, Mazinis M. Removal efficacy of various calcium hydroxide/chlorhexidine medicaments from the root canal. Int Endod J. 2006;39(1):55-61. doi: 10.1111/j.1365-2591.2005.01049.x.

21. Yaylali IE, Kececi AD, Kaya BU. Ultrasonically activated irrigation to remove calcium hydroxide from apical third of human root canal system: A systematic review of in vitro studies. J Endod. 2015;41(10):1589-99. doi: 10.1016/j.joen.2015.06.006.

22. Khaleel HY, Al-Ashaw AJ, Yang Y, Pang AH, Ma JZ. Quantitative comparison of calcium hydroxide removal by EndoActivator, ultrasonic and ProTaper file agitation techniques: an in vitro study. J Huazhong Univ Sci Technolog Med Sci. 2013;33(1):142-5. doi: 10.1007/s11596-013-1087-x.

23. Bottcher DE, Rahde NM, Grecca FS. Calcium hydroxide removal: effectiveness of ultrasonic and manual techniques. Rev Odonto Cienc. 2012; 27(2):152-5. doi: 10.1590/ S1980-65232012000200011.

24. Ma J, Shen Y, Yang Y, Gao Y, Wan P, Gan Y, et al. In vitro study of calcium hydroxide removal from mandibular molar root canals. J Endod. 2015;41(4):553-8. doi: 10.1016/j.joen.2014.11.023.

25. Pabel AK, Hülsmann M. Comparison of different techniques for removal of calcium hydroxide from straight root canals: an in vitro study. Odontology. 2017; 105(4):453-9. doi: 10.1007/s10266-017-0293-6.

26. Eren SK, Aksel H, Parashos P. A novel model for testing the efficiency of removal of calcium hydroxide from complex root canal anatomies. Australian Endodontic Journal. 2017; 43(1):5-10. doi: 10.1111/ aej.12189.

27. Wang Y, Guo L, Fang H, Zou W, Yang Y, Gao Y, et al. An in vitro study on the efficacy of removing calcium hydroxide from curved root canal systems in root canal therapy. Int J Oral Sci. 2017;9(2):110116. doi: 10.1038/ijos.2017.14.

28. Eymirli A, Nagas E, Uyanik MO, Cehreli ZF. Effect of laser-activated irrigation with ethylene diaminetetraacetic acid and phytic acid on the removal of calcium hydroxide and triple antibiotic paste from root dentin. Photomed Laser Surg. 2017;35(1):43-8. doi: $10.1089 /$ pho.2016.4146. 
Tsvetelina Borisova-Papancheva, Slavena Svetlozarova

29. Kuştarcı A, Er K, Siso SH, Aydın H, Harorlı H, Arslan D, et al. Efficacy of laser-activated irrigants in calcium hydroxide removal from the artificial grooves in root canals: An ex vivo study. Photomed Laser Surg. 2016;34(5):205-10. doi: 10.1089/ pho.2015.3951.

30. Kaptan F, Karapinar-Kazandag M, Kayahan MB, Bora T, Bayirli G. Potential of an Er:YAG Laser in the Removal of Calcium Hydroxide from Root Canals. Photomed Laser Surg. 2012;30(5):250-4. doi: 10.1089/pho.2011.3093.

31. Zorzin J, Wießner J, Wießner T, Lohbauer U, Petschelt A, Ebert J. Removal of radioactively marked calcium hydroxide from the root canal: influence of volume of irrigation and activation. J Endod. 2016;42(4):637-40. doi: 10.1016/j. joen.2016.01.005.

32. Faria G, Viola KS, Kuga MC, Garcia AJA, Daher VB, De Pasquali Leonardo MF, et al. Effect of rotary instrument associated with different irrigation techniques on removing calcium hydroxide dressing. Microsc Res Tech. 2014;77(8):642-6. doi: 10.1002/jemt.22382.

33. Capar ID, Ozcan E, Arslan H, Ertas H, Aydinbelge HA. Effect of different final irrigation methods on the removal of calcium hydroxide from an artificial standardized groove in the apical third of root canals. J Endod. 2014;40(3):451-4. doi: 10.1016/j. joen.2013.10.019.

34. Margelos J, Eliades G, Verdelis C, Palaghias G. Interaction of calcium hydroxide with zinc oxideeugenol type sealers: a potential clinical problem. J Endod. 1997;23(1):43-8. doi: 10.1016/ S0099-2399(97)80206-3.

35. Ballal NV, Kandian S, Mala K, Bhat KS, Acharya S. Comparison of the efficacy of maleic acid and ethylenediaminetetraacetic acid in smear layer removal from instrumented human root canal: a scanning electron microscopic study. J Endod. 2009;35(11):1573-6. doi: 10.1016/j.joen.2009.07.021.

36. Ballal NV, Kumar SR, Laxmikanth HK, Saraswathi MV. Comparative evaluation of different chelators in removal of calcium hydroxide preparations from root canals. Aust Dent J. 2012;57(3):344-8. doi: 10.1111/j.1834-7819.2012.01710.x.

37. Kuga MC, Tanomaru-Filho M, Faria G, Reis Só MV, Galletti T, Bavello JR. Calcium hydroxide intracanal dressing removal with different rotary instruments and irrigating solutions: a scanning elec- tron microscopy study. Brazilian Dental Journal. 2010; 21(4):310-4.

38. Topçuoğlu HS, Düzgün S, Ceyhanlı KT, Aktı A, Pala K, Kesim B. Efficacy of different irrigation techniques in the removal of calcium hydroxide from a simulated internal root resorption cavity. Int Endod J. 2015;48(4):309-16. doi: 10.1111/iej.12316.

39. Guelzow A, Stamm O, Martus P, Kielbassa AM. Comparative study of six rotary nickel-titanium systems and hand instrumentation for root canal preparation. Int Endod J. 2005;38(10):743-52. doi: 10.1111/j.1365-2591.2005.01010.x.

40. Eymirli A, Uyanik O, Nagas E, Tarhan SC. Effect of calcium hydroxide removal techniques on the bond strength of root canal sealers. J Adhes Sci Technol. 2017;31(11):1196-202. doi: 10.1080/01694243.2016.1249205.

41. Jainaen A, Palamara JE, Messer HH. Pushout bond strengths of the dentine-sealer interface with and without a main cone. Int Endod J. 2007;40(11):882-90. doi: 10.1111/j.1365-2591.2007.01308.x.

42. Gokturk H, Bayram E, Bayram HM, Aslan T, Ustun Y. Effect of double antibiotic and calcium hydroxide pastes on dislodgement resistance of an epoxy resin-based and two calcium silicate-based root canal sealers. Clin Oral Investig. 2017;21(4):127782. doi: 10.1007/s00784-016-1877-1.

43. Akcay M, Arslan H, Topcuoglu HS, Tuncay O. Effect of calcium hydroxide and double and triple antibiotic pastes on the bond strength of epoxy resin-based sealer to root canal dentin. J Endod. 2014;40(10):1663-7. doi: 10.1016/j.joen.2014.05.006.

44. Carvalho CN, Bauer J, Ferrari PHP, Souza SFC, Soares SP, Loguercio AD, et al. Influence of calcium hydroxide intracanal medication on bond strength of two endodontic resin-based sealers assessed by micropush-out test. Dent Traumatol. 2013;29(1):736. doi: 10.1111/j.1600-9657.2011.01109.x.

45. Calt $S$, Serper A. Dentinal tubule penetration of root canal sealers after root canal dressing with calcium hydroxide. J Endod. 1999; 25(6):431-3. doi: 10.1016/S0099-2399(99)80273-8.

46. Williams C, Loushine RJ, Weller RN, Pashley DH, Tay FR. A comparison of cohesive strength and stiffness of Resilon and gutta-percha. J Endod. 2006; 32(6):553-5. doi: 10.1016/j.joen.2005.08.002. 